\title{
The relationship between frailty, anxiety and depression, and health-related quality of life in elderly patients with heart failure
}

\author{
Izabella Uchmanowicz' \\ Robbert JJ Gobbens ${ }^{2,3}$ \\ 'Department of Clinical Nursing, \\ Wrocław Medical University, Wrocław, \\ Poland; ${ }^{2}$ Faculty of Health, Sports \\ and Social Work, Inholland University \\ of Applied Sciences, Amsterdam, \\ the Netherlands; ${ }^{3}$ Zonnehuisgroep \\ Amstelland, Amstelveen, the \\ Netherlands
}

This article was published in the following Dove Press journal:

Clinical Interventions in Aging

5 October 2015

Number of times this article has been viewed
Objective: Elderly people constitute over $80 \%$ of the population of patients with heart failure (HF). Frailty is a distinct biological syndrome that reflects decreased physiologic reserve and resistance to stressors. Moreover, frailty can serve as an independent predictor of visits to the emergency department, hospitalizations, and mortality. The purpose of this paper was to assess the relationship between frailty, anxiety and depression, and the health-related quality of life (HRQoL) of elderly patients with HF.

Patients and methods: The study included 100 patients (53 men and 47 women) with a diagnosis of HF. Frailty was measured using the Tilburg Frailty Indicator (TFI) scale. HRQoL was measured using the 36-Item Short Form Medical Outcomes Study Survey. To determine the prevalence of anxiety and depression, the Hospital Anxiety and Depression Scale was used.

Results: Frailty was found in $89 \%$ of the studied population. The study showed significant inverse correlations between the values of the physical component scale (PCS) domain results and TFI score, and a significant inverse correlation between the values of the mental component scale (MCS) domain and TFI score. When participants showed increased levels of frailty as measured by the TFI scale, there was also an increase in the levels of anxiety and depression. With increased anxiety and depression, there was deterioration in the quality of life of patients with HF.

Conclusion: Frailty has a negative impact on the HRQoL results of elderly patients with HF. The assessment of frailty syndrome, and anxiety and depression should be taken into account when estimating risk and making therapeutic decisions for cardiovascular disease treatment and care.

Keywords: frailty, health-related quality of life, heart failure, elderly, anxiety, depression

\section{Introduction}

Considering the increasing age of individuals affected with heart failure (HF), a specific approach to their treatment is required, with more attention being paid to geriatric conditions such as poor mobility, multiple disabilities, and cognitive impairment. ${ }^{1,2}$ Frailty syndrome (FS) is a distinct biological condition that reflects decreased physiological reserve and resistance to stressors. Frailty occurs more frequently among patients with HF than among the general population and serves as an independent predictor of visits to the emergency department, hospitalizations, and mortality. ${ }^{1-3}$ It has shown to occur frequently in patients with $\mathrm{HF}$, with prevalence ranging from $15 \%$ to $74 \%$, depending on the studied population and the method of assessment. Elderly people constitute over $80 \%$ of the population of patients with HF. ${ }^{4}$ The relationship between frailty and HF is complex and the two factors may exacerbate one another. Some
Correspondence: Izabella Uchmanowicz Department of Clinical Nursing, Wrocław Medical University, Bartla 5 Street, Wrocław 5 I-618, Poland Tel +48 7I 7841824

Email izabella.uchmanowicz@am.wroc.pl 
studies have shown that frailty is independently associated with adverse outcomes in patients with HF including hospitalization and mortality. ${ }^{1,5,6}$ Due to its prognostic role, the identification of frailty is of crucial importance in patients with HF. Additionally, the identification of individuals who are at an increased risk for frailty is important, as they may benefit from early therapeutic intervention. In this paper, we discuss the influence of frailty on health-related quality of life (HRQoL) results. Adverse outcomes of frailty may have a negative impact on HRQoL.

Gobbens et $\mathrm{al}^{7}$ reported strong associations between Tilburg Frailty Indicator (TFI) scores (frailty) and quality of life (QoL), disability, and the presence of nursing and informal care. The prevalence of depression and anxiety is high in chronic patients with HF (10\%-60\% depression; $11 \%-45 \%$ anxiety); for this reason, we included these variables in the present study to determine if depression and anxiety might be correlated with FS and HRQoL.

Comorbid depression and anxiety are associated with increased mortality and health care utilization and have an impact on QoL. On average, patients with HF have much higher anxiety levels than healthy older adults. ${ }^{8}$ Few researchers have reported that the presence of anxiety symptoms is an independent predictor of worsening functional status, poorer HRQoL and more frequent rehospitalizations. ${ }^{9-11}$ Within the extensive literature on frailty, there has been little research on the impact of frailty on the HRQoL of patients with HF. This reflects a lack of knowledge about the special needs of patients with HF and FS. HRQoL has been defined as an individual's perception of their position in life in the context of the culture and value system in which they live, and in relation to their goals, expectations, standards, and concerns. ${ }^{12} \mathrm{HRQoL}$ is an important variable that may predict adverse outcomes in terms of how they predispose patients to progressing in functional and mental independence. Therefore, the purpose of this study was to assess the relationship between frailty, anxiety and depression, and the HRQoL of patients with HF. To our knowledge, this is the first study on this subject.

\section{Patients and methods Study design}

Nurses administered the questionnaires used in the study. All patients gave their written informed consent for participation in the study. The inclusion criteria were age $\geq 60$ years, diagnosis of HF, and written informed consent for participation in the study. The exclusion criteria were communication barriers (eg, deafness or blindness) or problems related to manual dexterity. Also, we excluded patients who had stroke, obturative pulmonary disease previously. The protocol for the study was approved by the Local Bioethical Committee of Wroclaw Medical University - Nbr521/2014.

\section{Frailty instrument}

Frailty was measured using the TFI scale (Polish version). ${ }^{13}$ TFI consists of two parts: one addresses the sociodemographic characteristics of a participant (sex, age, marital status, country of origin, educational level, and monthly income), as well as the potential determinants of frailty. The second part addresses the components of frailty. Part two of the TFI comprises 15 self-reported questions, divided into three domains. The physical domain ( $0-8$ points) consists of eight questions related to physical health, unexplained weight loss, difficulty walking, balance, hearing problems, vision problems, strength in hands, and physical tiredness. The psychological domain ( $0-4$ points) comprises four items related to cognition, depressive symptoms, anxiety, and coping. The social domain ( $0-3$ points) comprises three questions related to living alone, social relations, and social support. Eleven items of part two of the TFI have two response categories (yes and no), while the other items have three (yes, no, and sometimes). "Yes" or "sometimes" responses were scored 1 point each, while "no" responses were scored 0 . The instrument's total score ranged from 0 to 15: the higher the score, the higher one's frailty. Frailty was diagnosed when the total TFI score was 5. Previous research suggests that the TFI is a valid and reliable instrument for measuring frailty. ${ }^{14}$

\section{QoL instrument}

HRQoL was measured using the 36-Item Short Form Medical Outcomes Study Survey (SF-36) (Polish version). ${ }^{15}$ The SF-36 measures the following eight generic health categories: physical functioning, role limitations due to physical problems, bodily pain, general perception of health, vitality, social functioning, role limitations due to emotional problems and mental health (MH). Subscale scores range from 0 to 100 , with higher scores signifying greater HRQoL. The physical subscales, measuring physical problems, pain, and self-rated health constitute a PCS. The mental subscales, measuring daily functioning in relation to psychological issues and vitality, constitute a mental component scale (MCS). ${ }^{15}$

\section{Psychological instrument for anxiety and depression}

To determine the prevalence of anxiety and depression, we used the Hospital Anxiety and Depression Scale (HADS), 
which distinguishes itself from all other scales by its ability to assess anxiety and depression without investigating somatic symptoms. HADS is often used to analyze a variety of diseases in the clinical setting. The scale consists of a series of 14 questions, seven of which are related to anxiety (HAD-A), while the other seven questions are related to depression (HAD-D). The creators of the scale considered a score of less than 8 to indicate the lack of any mental disorder, a score equal to or greater than 8 to indicate that a disorder was "probably" present, while a score greater than 10 was considered to indicate that a patient was "highly likely" to have a disorder. ${ }^{16,17}$

\section{Participants}

The study included 100 patients ( 53 men and 47 women) with a diagnosis of HF. All of the participants agreed to participate in the project and answered all the questions included in the questionnaires that were administrated.

\section{Statistical analysis}

Statistical analyses were performed using the Statistica v10 package (StatSoft, Tulsa, OK, USA). Descriptive statistics were presented by nonfrail and frail patients, and differences between groups were assessed via Mann-Whitney $U$ test or Student's $t$-test for independent samples and Pearson's chi-square tests or Fisher's exact tests for independence. Differences in mean scores on the SF-36 subscales by frailty status were also identified using a Mann-Whitney $U$ test. Multivariable models testing the effect of frailty status on the SF-36 summary scores were developed using multivariate linear regression analyses. In addition, to test the effect of frailty on each subscale of SF-36, we used stepwise multivariate linear regression analyses to measure the $R^{2}$ change of frailty.

\section{Results}

The study included 100 consecutive patients (mean age: nonfrail, $62.3 \pm 6.2$ years; frail, $67.9 \pm 10.7$ years). The majority of our participants were unmarried (widowed or divorced) $(n=64)$ (Table 1) and included 53 men and 47 women. All of the participants agreed to participate in the project and answered all the questions included in the questionnaires that were administrated.

Frailty was found in $89 \%$ of the studied population. The average results of TFI in the group with FS were $8.4 \pm 2.4$, and in nonfrail patients with TFI values of $3.2 \pm 0.9(P<0.001)$. The average value of HADS-anxiety in the group with FS was $9.5 \pm 4.5$. In the group of nonfrail $3.9 \pm 3.3(P<0.001)$.
Table I Sociodemographic and clinical characteristics of patients by frailty status

\begin{tabular}{|c|c|c|c|}
\hline \multirow[t]{2}{*}{ Variable } & \multicolumn{2}{|l|}{ Patients } & \multirow[t]{2}{*}{$P$-value } \\
\hline & $\begin{array}{l}\text { Nonfrail, } \\
n=11\end{array}$ & $\begin{array}{l}\text { Frail, } \\
\mathrm{n}=89\end{array}$ & \\
\hline Age (years), mean (SD) & $62.3(6.2)$ & $67.9(10.7)$ & $0.090^{\mathrm{a}}$ \\
\hline Sex & & & $0.142^{\mathrm{b}}$ \\
\hline Male $(n=53)$ & $8(72.7 \%)$ & $45(50.6 \%)$ & \\
\hline Female $(n=47)$ & $3(27.3 \%)$ & $44(49.4 \%)$ & \\
\hline Years of education, mean (SD) & $11.2(1.3)$ & II.5 (2.3) & $0.674^{a}$ \\
\hline Civil status & & & $0.166^{\mathrm{b}}$ \\
\hline Married $(n=36)$ & $2(18.2 \%)$ & $34(38.2 \%)$ & \\
\hline Unmarried $(n=64)$ & $9(81.8 \%)$ & $55(6 \mathrm{I} .8 \%)$ & \\
\hline $\begin{array}{l}\text { Number of hospitalizations } \\
\text { during I year, mean (SD) }\end{array}$ & $1.4(0.5)$ & $1.8(1.1)$ & $0.150^{\mathrm{a}}$ \\
\hline $\begin{array}{l}\text { Time from HF diagnosis } \\
\text { (years), mean (SD) }\end{array}$ & $7.7(4.2)$ & $9.8(6.0)$ & $0.352^{\mathrm{d}}$ \\
\hline Income (PLZ) & & & $0.826^{c}$ \\
\hline$<3,000 \mathrm{zł}(\mathrm{n}=97)$ & II (100.0\%) & $86(96.6 \%)$ & \\
\hline $3,000-5,000$ zł $(n=2)$ & $0(0.0 \%)$ & $2(2.3 \%)$ & \\
\hline$>5,000$ zł $(n=1)$ & $0(0.0 \%)$ & $\mathrm{I}(\mathrm{I} . \mathrm{I} \%)$ & \\
\hline NYHA class & & & $0.233^{c}$ \\
\hline$I(n=10)$ & $3(27.3 \%)$ & $7(7.9 \%)$ & \\
\hline II $(n=53)$ & 5 (45.4\%) & 48 (53.9\%) & \\
\hline III $(n=35)$ & $3(27.3 \%)$ & $32(36.0 \%)$ & \\
\hline IV (n=2) & $0(0.0 \%)$ & $2(2.2 \%)$ & \\
\hline \multicolumn{4}{|l|}{ Medication } \\
\hline Diuretics $(n=84)$ & $9(81.8 \%)$ & 75 (84.3\%) & $0.557^{b}$ \\
\hline Beta-blockers $(n=87)$ & II (I00\%) & $76(85.4 \%)$ & $0.198^{b}$ \\
\hline ACE/ARB $(n=64)$ & $6(54.6 \%)$ & $58(65.2 \%)$ & $0.352^{\mathrm{b}}$ \\
\hline Digoxin $(n=13)$ & I (9.1\%) & $12(13.5 \%)$ & $0.565^{b}$ \\
\hline \multicolumn{4}{|l|}{ HADS } \\
\hline Anxiety, mean (SD) & $3.9(3.3)$ & $9.5(4.5)$ & \\
\hline Depression, mean (SD) & $3.4(2.8)$ & $8.8(4.9)$ & $0.00 I^{d}$ \\
\hline \multicolumn{4}{|l|}{ SF-36 } \\
\hline PCS, mean (SD) & $52.4(19.5)$ & $32.8(17.0)$ & $0.00 \mathrm{I}^{\mathrm{a}}$ \\
\hline MCS, mean (SD) & $67.0(17.9)$ & $42.9(16.6)$ & $<0.00 \mathrm{I}^{\mathrm{a}}$ \\
\hline TFI score, mean (SD) & $3.2(0.9)$ & $8.4(2.4)$ & $<\mathbf{0 . 0 0}^{\mathrm{a}}$ \\
\hline
\end{tabular}

Notes: ${ }^{a} t$-test; ' ${ }^{2}$ Fisher's exact test; 'Pearson's chi-square; ${ }^{d}$ Mann-Whitney $U$ test. Data in bold indicates statistical significance.

Abbreviations: HF, heart failure; PLZ, Polish zloty; NYHA, New York Heart Association; SF-36, Short Form 36; HADS, Hospital Anxiety and Depression Scale; MCS, mental component scale; PCS, physical component scale; TFI, Tilburg Frailty Indicator; ACE, angiotensin-converting enzyme; ARB, angiotensin receptor blocker.

The average value of the HADS-depression in the group with FS was $8.8 \pm 4.9$ and in the nonfrail group was $3.4 \pm 2.8$ $(P<0.001)$ (Table 1).

The HRQoL results for PCS in frail group were: 67.0 \pm 19.5 , nonfrail: $52.4 \pm 19.5(P<0.001)$. The HRQoL results in MCS in frail group were: $42.9 \pm 16.6$, nonfrail: $52.4 \pm 19.5(P<0.001)$ (Table 1$)$.

The study showed significant inverse correlations between the values of the PCS domain results and TFI score $(r=-0.66, P<0.001)$ (Table 2$)$ and significantly inverse correlation between values of the MCS domain and TFI score $(r=-0.68, P<0.001)$ (Table 2$)$. With an increase in the value 
Table 2 Correlations between frailty, anxiety and depression, and health-related quality of life $(n=100)$

\begin{tabular}{lllll}
\hline Variable & $\begin{array}{l}\text { SF-36 } \\
\text { PCS }\end{array}$ & $\begin{array}{l}\text { SF-36 } \\
\text { MCS }\end{array}$ & $\begin{array}{l}\text { HADS- } \\
\text { anxiety }\end{array}$ & $\begin{array}{l}\text { HADS- } \\
\text { depression }\end{array}$ \\
\hline TFI score & $-0.66 * * *$ & $-0.68 * * *$ & $0.60^{* * * *}$ & $0.66 * * *$ \\
SF-36 total & $0.92 * * *$ & $0.94 * * *$ & $-0.60^{* * *}$ & $-0.73 * * *$ \\
SF-36 PCS & & $0.75 * * *$ & $-0.5 I^{* * *}$ & $-0.61^{* * *}$ \\
SF-36 MCS & & & $-0.59 * * *$ & $-0.74 * * *$ \\
HADS-anxiety & & & & $0.73 * * *$ \\
HADS-depression & & & & \\
\hline
\end{tabular}

Notes: ***p<0.001.

Abbreviations: TFI, Tilburg Frailty Indicator; PCS, physical component scale; MCS, mental component scale; SF-36, Short Form 36; HADS, Hospital Anxiety and Depression Scale.

of TFI, the QoL among patients with HF deteriorated. Our analysis showed significant positive correlations between TFI scores, HADS-anxiety results $(r=0.60, P<0.001)$, and HADS-depression results $(r=0.66, P<0.001)$.

We found that a higher TFI score is a strong predictor of worsening PCS and MCS results (Table 2). When the participants showed increased levels of frailty measured by the TFI scale, there was also an increase in the level of anxiety and depression.

Our analysis showed a significant inverse correlation between PCS domain values and the values of HADSanxiety $(r=-0.51)$ and HADS-depression $(r=-0.61$, $P<0.001$; Table 2). There was also a significant inverse correlation between MCS domain values and the values of HADS-anxiety ( $r=-0.59)$ and HADS-depression $(r=-0.74$, $P<0.001$ ) (Table 2). An increase in anxiety and depression showed deterioration in the QoL in patients with HF.

Multiple regression analyses showed that the parameters that exerted a significant independent effect on the level of the PCS scores were those derived from the results of the TFI questionnaire (Table 3). Multiple regression analyses showed that the parameters that exerted a significant independent effect on the level of the MCS scale scores were the TFI and the HADS-depression results (Table 4). Multiple regression analyses showed that the parameters that exerted a significant independent effect on the level of the TFI were age $>65$ years PCS score and HADS-anxiety (Table 5).

Table 3 Regression summary for dependent variable: SF-36 PCS

\begin{tabular}{|c|c|c|c|c|c|c|}
\hline & Beta & SE of Beta & B & SE of $B$ & $t(97)$ & P-value \\
\hline Intercept & & & 64.8 & 4.2 & 15.484 & $<0.001$ \\
\hline TFI score & -0.392 & 0.101 & -2.57 & 0.662 & -3.886 & $<0.001$ \\
\hline HADS-depression & -0.328 & 0.101 & -1.19 & 0.366 & -3.250 & 0.002 \\
\hline
\end{tabular}

Notes: $R=0.655, R^{2}=0.429$, adjusted $R^{2}=0.417, F(2.97)=6.4, P<0.00001$.

Abbreviations: SE, standard error; TFI, Tilburg Frailty Indicator; HADS, Hospital Anxiety and Depression Scale; SF, Short Form 36; PCS, physical component scale.
Table 4 Regression summary for dependent variable: SF-36 MCS

\begin{tabular}{lllllll}
\hline & Beta & SE of Beta B & \multicolumn{2}{l}{ SE of B $\boldsymbol{t}(\mathbf{9 7})$} & $P$-value \\
\hline Intercept & & & 78.1 & 3.6 & $21.81 \mathrm{I}$ & $<0.00 \mathrm{I}$ \\
TFI score & -0.348 & 0.086 & -2.29 & 0.566 & -4.044 & $<0.00 \mathrm{I}$ \\
HADS-depression & -0.492 & 0.086 & -1.79 & 0.313 & -5.729 & $<0.00 \mathrm{I}$ \\
\hline
\end{tabular}

Notes: $R=0.765, R^{2}=0.586$, adjusted $R^{2}=0.577, F(2.97)=68.5, P<0.0000 \mathrm{I}$.

Abbreviations: SE, standard error; TFI, Tilburg Frailty Indicator; HADS, Hospital Anxiety and Depression Scale; SF, Short Form 36; MCS, mental component scale.

In the regression analysis, higher HADS results were predictive of frailty. Additionally, older age was a predictor of higher results in the TFI score. Lower TFI scores correlated with higher PCS results. Other sociodemographic variables had no impact on the results.

\section{Discussion}

The purpose of this study was to assess the relationship between frailty, and anxiety and depression on the one hand, and HRQoL on the other, in patients with HF. The instrument we used to assess frailty (TFI) is based on the definition of "frailty" as a dynamic state affecting an individual who experiences losses in one or more domains of human functioning (physical, psychological, and social), which are caused by the influence of a range of variables and which increases the risk of adverse outcomes. ${ }^{18}$ Several studies have documented an association between the FS and cardiovascular disease. This relationship is particularly strong in the case of $\mathrm{HF},{ }^{19-21}$ ranging from $15 \%$ to $74 \%$.

HF adversely affects the patients' lives, severely restricting them in many areas of activity and social functioning, which lowers their QoL. ${ }^{22,23}$

Depression increases the frequency of rehospitalization in patients with HF, according to Johnson et $\mathrm{al}^{24}$ by a factor of 1.5 compared to patients with HF without depression. This remains true even when cooperation between the physician and the patient is good, and the patient takes medication regularly. Patients with HF often experience symptoms of depression and cognitive disorders, which interfere with compliance with treatment and lower the QoL. The

Table 5 Regression summary for dependent variable: TFI score

\begin{tabular}{lllllll}
\hline & Beta & SE of Beta & B & SE of B & $\mathbf{t ( 9 6 )}$ & P-value \\
\hline Intercept & & & 3.20 & 1.70 & 1.899 & $0.06 \mathrm{I}$ \\
Age & 0.280 & 0.070 & 0.08 & 0.02 & 4.188 & $<0.001$ \\
PCS score & -0.385 & 0.083 & -0.06 & 0.01 & -4.639 & $<0.001$ \\
HADS-anxiety & 0.384 & 0.080 & 0.23 & 0.05 & 4.775 & $<0.001$ \\
\hline
\end{tabular}

Notes: $R=0.776, R^{2}=0.602$, adjusted $R^{2}=0.590, F(3.96)=48.4, P<0.0000 \mathrm{I}$.

Abbreviations: TFI, Tilburg Frailty Indicator; SE, standard error; PCS, physical component scale; HADS, Hospital Anxiety and Depression Scale. 
authors report that depressed patients are not as careful as nondepressed patients when it comes to medication, ${ }^{25}$ and they do not take medication as commonly as those who are not depressed ( $75 \%$ vs $21 \%, P<0.01) .{ }^{26} \mathrm{We}$ found that being frail was significantly correlated with lower scores in perception in the MCS, PCS and lower scores in the SF-36, when compared to patients who were not frail (Tables 3 and 4). Low scores on the MCS and PCS were also associated with a higher score in depression and anxiety. Other authors report that the deteriorating health of patients with HF makes them realize the possibility of death, which leads to depression, anxiety, and sleep disorders, that is, a further deterioration of psychosocial health. ${ }^{27}$

\section{Implications for practice}

Little is known about the relationship between frailty status and the different aspects of QoL in general, as well as on the interventions for improving QoL in frail patients with HF. We believe that it is of great importance to pay special attention to the distinctive needs of frailty patients in the context of HF to improve functional and mental independence, as well as QoL. Implementation of the early detection of frailty within this group remains an issue of paramount importance, as this approach may prevent functional decline and improve or maintain the individual's independence.

\section{Study limitations}

We are well aware of the potential limitations of this study. The most important of these stem from the fact that our study sample was relatively small and recruited from a single center. Additionally, most of the patients were frail (89\%). We plan to extend our research on this subject in the future.

\section{Conclusion}

Frailty has a negative impact on the HRQoL results of elderly patients with HF. The assessment of FS and anxiety and depression should be taken into account when estimating risk and making therapeutic decisions for cardiovascular disease treatment and care.

\section{Disclosure}

The authors report no conflicts of interest in this work.

\section{References}

1. Cacciatore F, Abete P, Mazzella F, et al. Frailty predicts long-term mortality in elderly subjects with chronic heart failure. Eur J Clin Invest. 2005;35(12):723-730.

2. Lupon J, Gonzalez B, Santaeugenia S, et al. Prognostic implication of frailty and depressive symptoms in an outpatient population with heart failure. Rev Esp Cardiol. 2008;61(8):835-842.
3. McNallan SM, Chamberlain AM, Gerber Y, et al. Measuring frailty in heart failure: a community perspective. Am Heart J. 2013;166(4): 768-774.

4. Go AS, Mozaffarian D, Roger VL, et al. Heart disease and stroke statistics-2013 update: a report from the American Heart Association. Circulation. 2013;127(1):e6.

5. Lien CTC, Gillespie ND, Struthers AD, McMurdo MET. Heart failure in frail elderly patients: diagnostic difficulties, co-morbidities, polypharmacy and treatment dilemmas. Eur J Heart Fail. 2002;4(1): 91-98.

6. Pulignano G, Del Sindaco D, Di Lenarda A, et al. Usefulness of frailty profile for targeting older heart failure patients in disease management programs: a cost-effectiveness pilot study. J Cardiovasc Med. 2010; 11(10):739-742.

7. Gobbens RJ, van Assen MA, Luijkx KG, Wijnen-Sponselee MT, Schols JM. The Tilburg Frailty Indicator: psychometric properties. J Am Med Dir Assoc. 2010;11(5):344-355.

8. Moser DK, Dracup K, Evangelista LS, et al. Comparison of the prevalence of symptoms of depression, anxiety, and hostility in elderly patients with heart failure, myocardial infarction, and a coronary artery bypass graft. Heart Lung. 2010;39(5):378-385.

9. Shen BJ, Eisenberg SA, Maeda U, et al. Depression and anxiety predict decline in physical health functioning in patients with heart failure. Ann Behav Med. 2011;41(3):373-382.

10. Moser DK, Heo S, Lee KS, et al. It could be worse ... lot's worse!' Why health-related quality of life is better in older compared with younger individuals with heart failure. Age Ageing. 2013;42(5):626-632.

11. Tsuchihashi-Makaya M, Kato N, Chishaki A, et al. Anxiety and poor social support are independently associated with adverse outcomes in patients with mild heart failure. Circ J. 2009;73(2):280-287.

12. WHOQOL group. World Health Organization Quality of Life assessment (WHOQOL): position paper from the World Health Organization. Soc Sci Med. 1995;41(10):1403-1409.

13. Uchmanowicz I, Jankowska-Polańska B, Łoboz-Rudnicka M, Manulik S, Łoboz-Grudzień K, Gobbens RJJ. Cross-cultural adaptation and reliability testing of the Tilburg Frailty Indicator for optimizing care of Polish patients with frailty syndrome. Clin Interv Aging. 2014;9: 997-1001.

14. Gobbens RJ, van Assen MA, Luijkx KG, Schols JM. The predictive validity of the Tilburg Frailty Indicator: disability, health care utilization, and quality of life in a population at risk. Gerontologist. 2012; 52(2):619-631.

15. McHorney CA, Ware JE Jr, Raczek AE. The MOS 36-Item Short-Form Health Survey (SF-36): II. Psychometric and clinical tests of validity in measuring physical and mental health constructs. Med Care. 1993; 31(3):247-263.

16. Zigmond AS, Snaith RP. The Hospital Anxiety and Depression Scale. Acta Psychiatr Scand. 1983;67(6):361-370.

17. Bjelland I, Dahl AA, Haug TT, Neckelmann D. The validity of the Hospital Anxiety and Depression Scale. An updated literature review. J Psychosom Res. 2002;52(2):69-77.

18. Gobbens RJ, Luijkx KG, Wijnen-Sponselee MT, Schols JM. Toward a conceptual definition of frail community dwelling older people. Nurs Outlook. 2010;58(2):76-86.

19. Altimir S, Lupon J, Gonzalez B, et al. Sex and age differences in fragility in a heart failure population. Eur J Heart Fail. 2005;7(5):798-802.

20. Newman AB, Gottdiener JS, McBurnie MA, et al. Associations of subclinical cardiovascular disease with frailty. J Gerontol A Biol Sci Med Sci. 2001;56(3):M158-M166.

21. Woods NF, LaCroix AZ, Gray SL, et al. Frailty: emergence and consequences in women aged 65 and older in the Women's Health Initiative Observational Study. J Am Geriatr Soc. 2005;53(8):1321-1330.

22. Dracup K, Walden J, Stevenson L, Bracht M. Quality of life in patients with advanced heart failure. J Heart Lung Transplant. 1992;11: 1273-1279.

23. Ward C. The quality of life in heart failure. Just talking about it will not make it better. Eur J Heart Fail. 2004;6:535-537. 
24. Johnson TJ, Basu S, Pisani BA, et al. Depression predicts repeated heart failure hospitalizations. J Card Fail. 2012;18(3):246-52. doi:10.1016/j. cardfail.2011.12.005.

25. Cholowski K1, Cantwell R. Predictors of medication compliance among older heart failure patients. Int J Older People Nurs. 2007;2(4): $250-262$.
26. Nieuwenhuis MM, Jaarsma T, van Veldhuisen DJ, Postmus D, van der Wal MH. Long-term compliance with nonpharmacologic treatment of patients with heart failure. Am J Cardiol. 2012;110(3):392-397.

27. Berry C, McMurray J. A review of quality of life evaluations in patients with congestive heart failure. Pharmacoeconomics. 1999;16:247-271.

\section{Publish your work in this journal}

Clinical Interventions in Aging is an international, peer-reviewed journal focusing on evidence-based reports on the value or lack thereof of treatments intended to prevent or delay the onset of maladaptive correlates of aging in human beings. This journal is indexed on PubMed Central, MedLine,
CAS, Scopus and the Elsevier Bibliographic databases. The manuscript management system is completely online and includes a very quick and fair peer-review system, which is all easy to use. Visit http://www.dovepress. com/testimonials.php to read real quotes from published authors. 